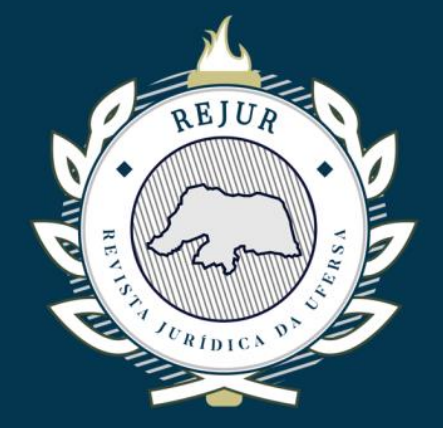

\title{
A ABERTURA DAS CONSTITUIÇÕES AO DIREITO INTERNACIONAL DOS DIREITOS HUMANOS:
} ENSAIO INTRODUTÓRIO

THE OPENING OF THE CONSTITUTIONS TO INTERNATIONAL HUMAN RIGHTS LAW: AN INTRODUCTORY ESSAY

\section{Breno Baía Magalhães*}

\section{RESUMO}

$\mathrm{O}$ artigo intenciona apresentar ideias iniciais acerca da reinterpretação das relações entre os ordenamentos nacionais e internacionais, levando em consideração novos paradigmas surgidos no contexto teórico contemporâneo. O artigo tenta apontar respostas ao seguinte problema: padrões de interação focadas em uma rejeição ou convergência dos ordenamentos parecem insuficientes para melhor proteger Direitos Humanos. Dessa forma, além de utilizar o tipo de pesquisa bibliográfica/jurisprudencial, o artigo parte do método comparado para sustentar que o constitucionalismo brasileiro precisa ser reinterpretado, especialmente por conta do impacto do direito internacional dos direitos humanos e da proteção multinível de direitos humanos, cuja produção jurisprudencial deverá ser considerada para fins de diálogo com decisões internas.

Palavras-chave: Direito Internacional dos Direitos Humanos; Direito Constitucional; Pluralismo; Diálogo.

\section{ABSTRACT}

The article intends to present initial ideas about the reinterpretation of the relations between national and international orders, taking into account new paradigms arising in the contemporary theoretical context. The article tries to offer answers to the following problem: patterns of interaction focused on a rejection or convergence of the order appear insufficient to better protect Human Rights. Thus, in addition to using the type of bibliographical / jurisprudential research, the article starts from the comparative method to maintain that Brazilian constitutionalism needs to be reinterpreted, especially due to the impact of international human rights law and multi-level human rights protection, whose Jurisprudential production should be considered for the purpose of dialogue with internal decisions.

Keywords: International Human Rights Law; Constitutional Law; Pluralism; Dialogue.

* Doutor em Direito Constitucional pela Universidade Federal do Pará (UFPA)

Professor de Direito Constitucional e Direitos Humanos da Universidade da Amazônia (UNAMA) e na Faculdade Integrada Brasil Amazônia (FIBRA).

brenobaiamag@gmail.com 


\section{SUMÁRIO}

INTRODUÇAO; 1 O REALINHAMENTO DO CONSTITUCIONALISMO BRASILEIRO, RELAÇÕES

INTERNACIONAIS, DIREITOS HUMANOS E REFORMAS CONSTITUCIONAIS: releitura de suas fundamentações teóricas; 2 PROTEÇÃO MULTINÍVEL DOS DIREITOS HUMANOS: O STF e os tratados internacionais de Direitos Humanos; 3 DIÁLOGO ENTRE PRECEDENTES COMO POSSÍVEL FORMA DE ARTICULAÇÃO; CONSIDERAÇÕES FINAIS; REFERÊNCIAS

\section{- INTRODUÇÃO}

Vivemos em uma época na qual a existência de uma miríade de ordenamentos jurídicos se entrelaça. Com frequência, normativas e decisões internacionais e supranacionais são citadas e utilizadas na interpretação das normas constitucionais domésticas. Dependendo da interpretação que se faz desta espécie de pluralismo, as consequências podem ser, simplesmente, formais. Dito em outras palavras, a citação e utilização dos padrões jurídicos internacionais podem ser encarados como simples "auxílios" na interpretação constitucional.

No entanto, a criação de ordens internacionais estruturadas institucionalmente com tribunais que interpretam tratados, cujas decisões são dirigidas aos Estados ratificadores de tal sistema, suscita a problemática das necessárias articulações das interpretações domésticas com as prescrições internacionais, da mesma forma que enseja a reinterpretação do ideário do monopólio estatal da produção jurídica e dos meios coercitivos.

A convivência de inúmeras ordens jurídicas dentro de um Estado não é algo novo ${ }^{1}$, mas é inegável que o fenômeno da globalização estreitou, ainda mais, as relações entre elas. 0 impacto das alterações nas instituições jurídicas produzidas pela globalização atingiu vários âmbitos, no entanto, o artigo irá limitar-se ao estudo da internacionalização dos Direitos Humanos, mais especificamente, nas relações entre o constitucionalismo brasileiro e o Sistema Interamericano de Proteção aos Direitos Humanos, analisando as formas de articulação da interpretação dos direitos humanos em ambos os níveis de proteção.

Os referidos sistemas internacionais de proteção, por sua vez, possuem âmbitos de atuação que coincidem com os das cartas de direitos fundamentais constitucionais, permitindo que nacionais oriundos de determinado Estado constitucional, com base nas tratativas internacionais de direitos humanos, apresentem denúncias a órgãos judiciais internacionais, com o objetivo de reparar e/ou fazer cessar violação de Direitos Humanos. A pessoa (ou determinados grupos), portanto, requer que instituições não constituídas pela ordenação constitucional controlem a atuação de órgãos constitucionais. Sua atuação tende a reposicionar as fundações da ideologia constitucionalista.

$\mathrm{O}$ artigo tem como objeto o estudo das possíveis formas de interação entre o Direito Internacional dos Direitos humanos e o Direito Constitucional, no caso, brasileiro. Justifica-se a análise dessas relações tendo em vista o seguinte problema: padrões de interação interordenamentos focadas em uma rejeição ou convergência parecem insuficientes para melhor proteger Direitos Humanos. Ou seja, rejeitar o direito internacional pode impedir que padrões

\footnotetext{
${ }^{1}$ Nesse sentido, ver o que Griffiths chama de "pluralismo em sentido fraco", identificado nos Estados europeus na época das colonizações do século XVI e XVII. GRIFFITHS, John. What is Legal Pluralism? Journal of Legal Pluralism, no 24, 1986, p. 1-55, p. 04.
} 
mais protetivos sejam colhidos das experiências de Tribunais Internacionais de Direitos Humanos. Por outro lado, sugerir que os Estados simplesmente aquiesçam de forma acrítica às estipulações internacionais ofusca o fato de as interpretações daqueles tribunais terem sido colhidas da jurisprudência de Cortes Constitucionais ou Supremas.

Dessa forma, além de utilizar o tipo de pesquisa bibliográfica/jurisprudencial, o artigo parte do método comparado para sustentar que o constitucionalismo brasileiro precisa ser reinterpretado, especialmente por conta do impacto do direito internacional dos direitos humanos e da proteção multinível de direitos humanos, cuja produção jurisprudencial deverá ser considerada para fins de diálogo com decisões internas.

Inicialmente, o artigo discorre sobre o impacto de reformas constitucionais na forma de um realinhamento dos pressupostos de nosso constitucionalismo, sugerindo uma reinterpretação de suas bases políticas e jurídicas, em seguida, desenvolve a ideia de proteção multinível de Direitos Humanos, que se caracteriza pela sobreposição de diversas declarações de direitos humanos e fundamentais que precisam ser interpretadas de forma harmoniosa. Uma das vias de interpretação pode ser catalisada pela supralegalidade dos tratados sobre direitos humanos. Por fim, as interações entre essas declarações deverão ser feitas por meio do diálogo entre precedentes, capazes de demonstrar a reconstrução interpretativa daquele direitos de acordo com as especificidades locais.

\section{REALINHAMENTO DO CONSTITUCIONALISMO BRASILEIRO, RELAÇÕES INTERNACIONAIS, DIREITOS HUMANOS E REFORMAS CONSTITUCIONAIS: RELEITURA DE SUAS FUNDAMENTAÇÕES TEÓRICAS}

Tradicionalmente relacionado às experiências revolucionárias burguesas do século XVIII, o constitucionalismo se apresentou como ideologia política importante na justificação do poder sem recursos a fundamentos atemporais, bem como estabeleceu meios jurídicos para sua contenção. A referida contenção do poder, quase sempre representada por Constituições escritas, ganhava corpo na separação de poderes e na garantia de direitos individuais. Em outros termos, a Constituição constituía o Estado laico por meio da soberania do povo, ao mesmo tempo em que controlava as ações políticas dos órgãos constituídos.

Ainda que agissem politicamente limitados pela Constituição no plano doméstico a partir do século XVIII, desde o século XVII, com a paz de Vestefália ${ }^{2}$, os Estados são considerados soberanos e independentes nas suas relações internacionais, ou seja, nenhum Estado estava subordinado ou poderia ser controlado por outro. O princípio da soberania nas relações internacionais, que estabeleceu o direito de independência em assuntos domésticos, foi o embrião do Direito Internacional clássico, caracterizado pelas regulamentações

\footnotetext{
${ }^{2}$ Com a paz de Vestefália (1648), tratados puseram fim à guerra dos trinta anos, o que significou, em suma, a laicização das relações internacionais entre os Estados europeus. A paz de Vestefália resultou em um direito de soberania - direito territorial unitário decorrente de um estado territorial. Permitiu, ademais, que as relações internacionais ocorressem de maneira, estritamente, jurídica e com base em regras estabelecidas a priori pelos tratados, amplamente discutidos pelos estados soberanos. Por conseguinte, os Estados são considerados iguais, suas soberanias são respeitadas e o direito internacional encontra limite de atuação, exatamente, nesses pontos. TEIXEIRA, Anderson Vinchinkeski. Teoria Pluriversalista do Direito Internacional. São Paulo: WMF Martins Fontes, 2011, p. 82-85.
} 
interestatais voluntárias e consentidas, relegando papel central aos Estados e secundário às pessoas.

Entretanto, o advento da 2a Guerra-Mundial alterou o referido paradigma com a internacionalização dos Direitos Humanos. Como aponta Slaughter ${ }^{3}$, as relações internacionais, assim como o direito internacional, a partir de 1945, sofreram mudanças em suas funções, na medida em que o modelo de soberania vestefaliano entrou em declínio, por conta da possibilidade de ineficácia regulativa dos assuntos domésticos de interesse mundial por parte dos Estados. Nesse sentido, a proteção internacional dos Direitos Humanos implica o compartilhamento de um importante traço do tradicional constitucionalismo estadual com os sistemas internacionais ou supranacionais: a limitação do poder por meio de direitos.

Aliado à expansão dos Direitos Humanos no âmbito internacional, o acirramento da faceta econômica da globalização também alterou, significativamente, a compreensão sustentada linhas atrás do que seria o constitucionalismo. Os ideais de liberação dos mercados e descentralizadores expostos pelo Consenso de Washington foram incorporados por vários Estados, especialmente, naqueles ditos emergentes, no sentido de liberalizar mercados e enxugar a intervenção estatal na economia. As alterações de regras constitucionais, privatizações e concessões de serviços públicos, transferiram para entes privados, geralmente, não ligados (ao menos diretamente) a uma base territorial específica, poderes anteriormente exclusivos aos órgãos estatais, acarretando sensível alteração do poder de intervenção do Estado na atividade econômica ${ }^{4}$. Os reflexos da globalização econômica, neste contexto, foram condensados em importantes e sucessivas reformas constitucionais formais.

Obviamente, os dois fenômenos anteriormente descritos influenciam a interpretação da Constituição de 1988.

No julgamento da ADC $\mathrm{n}$ - 19/DF, o relator, Ministro Marco Aurélio, declarou a constitucionalidade da Lei Federal 11.340/06 (Lei Maria da Penha), sustentando, entre outros argumentos, que o Estado brasileiro firmara compromisso internacional de dar concretização à determinação do art. 07, c, da Convenção Interamericana para Prevenir, Punir e Erradicar a Violência Contra a Mulher, incorporada ao ordenamento brasileiro por meio do Decreto Presidencial no 1.973, 01/08/96. Ainda que o relator não tenha citado como fundamento do seu voto o Relatório 54/01, da Comissão Interamericana de Direitos Humanos, o último foi utilizado pelo Ministro Celso de Mello, inclusive com a leitura de trecho substancial sobre a responsabilidade do Estado brasileiro e sobre as recomendações da Comissão ${ }^{5}$, uma delas, a criação de uma lei penal que tratasse sobre o tema.

A Ministra Carmen Lúcia, no julgamento da ADPF no 101/DF, oportunidade em que declarou inconstitucionais decisões judiciais que permitiram a importação de pneus usados não oriundos do MERCOSUL para o Brasil, interpretou o histórico da legislação ambiental nacional acerca da proibição de importação de bens de consumo usados como fruto e reflexo

\footnotetext{
${ }^{3}$ SLAUGHTER, Anne-Marie. Sovereignty and Power in a Networked World Order. Stanford Journal of International Law, n. 40, 2004, p.283-327, p. 284.

${ }^{4}$ Nesse sentido, cf. WALKER, Neil. Beyond Boundary Disputes and Basic Grids: Mapping the Global Disorder of Normative Orders, Vol. 6, no 3 e 4, International Journal of Constitution Law, 373-396, 2008, p. 373-374.

${ }^{5}$ Como exemplo, citamos os pontos do relatório mais relevantes para o argumento: "b) Simplificar os procedimentos judiciais penais a fim de que possa ser reduzido o tempo processual, sem afetar os direitos e garantias de devido processo; c) O estabelecimento de formas alternativas às judiciais, rápidas e efetivas de solução de conflitos intrafamiliares, bem como de sensibilização com respeito à sua gravidade e às conseqüências penais que gera".
} 
direto das normas internacionais sobre a matéria, especialmente, a Convenção da Basiléia, de 1989.

Ademais, como reforço à interpretação sobre proteção ao meio ambiente, a relatora citou a decisão da Organização Mundial de Comércio que, ao negar recurso da União Europeia, que intencionava quebrar o privilégio das importações de pneus remoldados detido pelos membros do MERCOSUL, concluiu que o Brasil demonstrou que a proibição de importação de pneus reformados foi considerada 'necessária' nos termos do Art. XX(b) ${ }^{6}$, do GATT (General Agreement on Tariffs and Trade), para a proteção do meio ambiente. Todavia, a organização ressaltou que o Brasil precisava estabelecer medidas que tornassem a disputa comercial igualitária e que as decisões judiciais que permitiam a importação de pneus usados oriundos da União Europeia contrariavam o objetivo da política de proteção ambiental considerada em conformidade com o GATT ${ }^{7}$.

Por fim, a Ministra julgou que as normas que adequaram a legislação nacional à decisão proferida pelo Tribunal Arbitral do Mercosul, que possibilitou a importação de pneus recauchutados e usados remoldados originários de integrantes do Mercosul, eram constitucionais, não obstante ter decidido que todos os pneus usados, inclusive os remoldados e recauchutados, não poderiam ser importados, tendo em vista a proteção dos direitos ao meio ambiente equilibrado e à incolumidade da saúde. A aparente incongruência se justificaria, nos termos do voto da Relatora, pelo fato de o Brasil ter aderido à jurisdição do Tribunal Arbitral do Mercosul, bem como pelo fato de que tal decisão e a portaria SECEX 35/2006 não terem sido impugnadas na inicial (tal portaria registrou a exceção, determinada pela decisão do Tribunal Arbitral, sobre a importação dos pneus usados oriundos do Mercosul).

As problemáticas enfrentadas pelo constitucionalismo contemporâneo esboçadas nos parágrafos anteriores são observadas, em alguma medida, nos exemplos das decisões do STF citadas mais acima, das seguintes formas: 1) a propositura da ADC $n=19 / D F$ pelo Presidente da República, que, na inicial, citou como justificativa para a existência da lei o relatório da Comissão Interamericana de Direitos Humanos, pode demonstrar que o pedido pela constitucionalidade da medida tenha como fundamento impedir que órgãos do Estado brasileiro (representados pelo Judiciário) declarem inconstitucional legislação requerida por instância supranacional que, caso fosse retirada do ordenamento brasileiro, poderia acarretar uma futura condenação pela Corte Interamericana de Direitos Humanos e 2) no caso da ADPF no 101/DF, a não inclusão, no pedido do Presidente da República, das portarias que excepcionaram a importação de pneus usados do Mercosul, bem como a declaração de sua constitucionalidade, demonstram que o Brasil aquiesceu na diminuição de seu poder

\footnotetext{
${ }^{6}$ Subject to the requirement that such measures are not applied in a manner which would constitute a means of arbitrary or unjustifiable discrimination between countries where the same conditions prevail, or a disguised restriction on international trade, nothing in this Agreement shall be construed to prevent the adoption or enforcement by any contracting party of measures: (...) (b) necessary to protect human, animal or plant life or health. (grifo nosso).

${ }^{7}$ O ministro Joaquim Barbosa, por exemplo, ao tratar do cabimento da ADPF, salientou, interpretando o requisito de inexistência de outro meio efetivo para sanar os descumprimentos aos preceitos fundamentais, que a possibilidade de condenação do Brasil na OMC, no que tange a manutenção de tratamentos discriminatórios injustificados entre os Estados-membros da União Europeia em relação aos do MERCOSUL, seria um dos fatores importantes para a interpretação daquele requisito legal (art. 4, § 10, da lei 9.882/99). Ressalte-se, como descrito na nota anterior, que as exceções às práticas comerciais baseadas na proteção ao meio ambiente serão consideradas legítimas, caso não se configurem como restrições comerciais disfarçadas.
} 
normativo na proteção do meio ambiente, além de reconhecer que a manutenção das decisões judiciais contrárias aos referidos atos normativos poderia acarretar condenações na OMC.

Diante do exposto nos parágrafos anteriores, o constitucionalismo brasileiro precisa ser reinterpretado em articulação com o direito internacional, a fim de dar conta das alterações paradigmáticas que ocorreram desde meados do século passado.

Com a globalização, as distâncias diminuíram, as comunicações tornaram-se mais rápidas, os avanços tecnológicos constantes, a economia mais dinâmica e os problemas que dela advêm tornaram-se comuns. Problemas comuns não no sentido de triviais, mas de problemas compartilhados pelos Estados.

As interações políticas, sociais e jurídicas no mundo globalizado não se encerram mais dentro das estruturas constitucionais dos Estados, tornando possível que questões econômicas, de direitos fundamentais, ou de migrações, surtam efeitos em diferentes partes do globo, ainda que tais Estados permaneçam regidos, no plano político, pela ideia de soberania.

Ainda que a globalização não tenha sido a causa direta de importantes alterações no trato dos Direitos Humanos no âmbito internacional ${ }^{8}$, o fenômeno é importante para demonstrar que não podemos olhar para o novo com lentes antigas ${ }^{9}$. É problemático explicar a noção de soberania política em uma época em que importantes decisões para uma comunidade política são tomadas por órgãos internacionais, ou com base em uma noção defasada de Direito Internacional cujo objeto seria, tão somente, regular a relação entre Estados soberanos, e que esquece o importante papel condicionante dos Tratados sobre Direitos Humanos ${ }^{10}$.

\footnotetext{
${ }^{8}$ Globalização é um conceito plurívoco. De acordo com Faria o conceito, tal como o conhecemos hoje, ganha corpo quando a literatura anglo-saxã dos anos 80 observa o surgimento de uma nova economia política das relações internacionais. No entanto, o autor considera que o fenômeno não é novo, pois já existia no período dos antigos impérios e assumiu várias formas até meados do século XX (expansão da cartografia, sistemas internacionais de câmbio, mercantilismo e colonialismo europeu). $O$ que pode ser considerado novo é sua aplicação a um inédito processo de superação das restrições de espaço pela minimização das limitações de tempo; as formas de interações transnacionais e as trocas desiguais entre os fatores de produção, com amplitude mundial. A partir da década de 70 ocorre a explosão da dívida federal norte-americana e com ela a obsolescência das normas regulatórias de intercâmbio econômico e internacional, consequentemente, os agentes produtivos e os governos se viram obrigados a reagir defensivamente aos graves problemas de custos industriais, culminando com uma profunda reorganização da divisão internacional do trabalho. Por fim, a crise do padrão monetário mundial e os choques do petróleo (73 e 79), surgidos com o fim do padrão da troca do ouro, possibilitaram a abertura dos mercados internos das economias desenvolvidas aos produtos industrializadas oriundos do terceiro mundo. FARIA, José Eduardo. O Direito na economia globalizada. São Paulo: Malheiros Editores, 1999, p. 60-63.

${ }^{9}$ De acordo com o Faria a globalização impôs a revisão de paradigmas da dogmática do direito, tendo em vista que a velha compreensão teórica do direito não dava conta das novas formas de interações sociais, políticas e econômicas decorrentes da globalização. Não consideramos que a globalização tenha sido o ponto de partida da internacionalização dos Direitos Humanos, mas apenas emprestamos o conceito de exaustão paradigmática para demonstrar que o fenômeno da globalização serviu para expor às escancaras a exaustão de modelos jurídicos que trabalham com a noção de soberania e com o conjunto binário monismo/dualismo para explicar as interrelações entre ordenamentos jurídicos internacionais e internos, pontos importantes para o trabalho. FARIA. $O$ Direito na economia globalizada, op. cit.

${ }^{10}$ HATHAWAY, Oona. Do Human Rights Treaties Make a Difference? The Yale Law Journal, Vol. 111, p.1935-2041, 2002.
} 
Nesse sentido, devemos repensar os princípios que podem explicar as novas formas de ordenações e interações entre as redes de Estados pós-vestfalia. No entanto, de acordo com Walker ${ }^{11}$ (2008), o grande problema da releitura dos princípios que podem reger as formas de inter-relações entre os Estados é que a tendência atual é a de desestabilização da rede básica (vestfaliana, de soberania política) em função de várias outras formas de estruturações incertas e pouco estabelecidas.

O primeiro abalo às compreensões clássicas pode ser sentido nas relações entre direito internacional e nacional. Tradicionalmente, e sempre tendo como base da classificação as decisões políticas internas como o critério aferidor mais importante, as relações entre as diferentes ordens jurídicas giravam em torno da contenda dualismo vs. monismo ${ }^{12}$, que estabelecia, no primeiro caso, que o ordenamento constitucional estabelecia a necessidade de incorporação do ato internacional por meio de um ato formal, geralmente, uma lei. 0 monismo, por sua vez, considerava que as ordens jurídicas internacionais e nacionais formavam um único conjunto, sendo, portanto, desnecessário um ato formal de incorporação. Todavia, tais descrições teóricas são por demais simples para explicar as complexas e densas interconexões entre ordens jurídicas ${ }^{13}$.

Tendo em vista que as formas de interação entre as ordens jurídicas nacionais e internacionais não podem mais ser explicadas pela simples remissão às soluções dualistas ou monistas, bem como ao metaprincípio da soberania para justificar as relações entre os Estados e suas normas jurídicas, Neil Walker, ao apresentar a existência de vários e possíveis metaprincípios concorrentes com o da soberania, salienta que os mesmos podem ser conflitantes:

\begin{tabular}{|l|l|l|}
\hline $\begin{array}{l}\text { Metaprincípio de autoridade } \\
\text { jurídica }\end{array}$ & $\begin{array}{l}\text { Aplicação forte e exclusiva } \\
\text { contrbuidorão moderada }\end{array}$ & $e$ \\
\hline
\end{tabular}

\footnotetext{
${ }^{11}$ WALKER, Beyond Boundary Disputes and Basic Grids. Op. cit.

${ }^{12}$ Significativa parte dos teóricos internacionalistas sobre o tema considera que a distinção entre monismo e dualismo está na forma de incorporação da norma internacional (monismo, desnecessário ato formal; dualismo, sendo necessária a intermediação de um ato formal incorporador - decreto de execução) e citam Hans Kelsen como partidário do monismo. No entanto, tal leitura parece apressada, já que, para Kelsen a forma de incorporação do direito internacional pelo direito interno era um assunto cabível à Constituição, que poderia, inclusive, exigir que um ato formal intermediasse a incorporação. 0 monismo kelseniano está ligado à ideia de que o Direito internacional e o interno fazem parte de um todo, na medida em que a norma hipotética fundamental dos Estados que encetam relações de direito internacional público será, aproximadamente, a seguinte: "que os estados se regulem por suas próprias constituições". As violações de uma norma internacional por conta de procedimentos constitucionais não poderiam ser revistas pelo direito internacional, pois inexiste norma capaz de revogar a Constituição local (lembremos do critério formal de validade do direito para Kelsen), nesses casos, cabíveis as sanções internacionais (represálias e guerra). Portanto, não são as formas de incorporação do ato que distinguem monismo e dualismo em Kelsen, mas a compreensão teórica de que apenas podemos falar de um direito internacional efetivo se pressupormos que este valida as normas jurídicas nacionais, na medida em que o direito internacional determinaria, enquanto ordenamento superior, a norma fundamental que permite aos estados confeccionarem suas próprias constitucionais, sob penas de sanções. Sobre o tema, cf. MAGALHÃES, Breno Baía. O sincretismo teórico na apropriação das teorias monista e dualista e sua questionável utilidade como critério para a classificação do modelo brasileiro de incorporação de normas internacionais. Revista de Direito Internacional, v. 12, no 02, p. 77-96, 2015.

${ }^{13}$ BOGDANDY, Armin Von. Pluralism, Direct Effect, and the Ultimate Say. International Journal of Constitutional Law, Vol. 6, n. 3 \& 4, 2008, 397-413, p. 399-400.
} 


\begin{tabular}{|l|l|l|}
\hline 1) estado soberano & $\begin{array}{l}\text { Realismo; anarquia do sistema } \\
\text { internacional }\end{array}$ & Internacionalismo liberal \\
\hline 2) hierarquia global & Governo mundial & $\begin{array}{l}\text { Estrutura piramidal com algumas } \\
\text { normas cosmopolitas }\end{array}$ \\
\hline 3) unipolar & Pax Americana & Hegemonia global liberal \\
\hline 4) regional & Ordem mundial dividida & $\begin{array}{l}\text { Novo balanceamento entre } \\
\text { diferentes concepções regionais } \\
\text { dardem } \\
\text { constitucional/internacional }\end{array}$ \\
\hline $\begin{array}{l}\text { 5) integridade } \\
\text { campo-jurídico discursivo } \\
\text { (ex.: } \\
\text { internacional) }\end{array}$ & $\begin{array}{l}\text { Campo jurídico particular como } \\
\text { mestre do discurso jurídico } \\
\text { entre as ordens }\end{array}$ & $\begin{array}{l}\text { Extensão e aplicação do discurso } \\
\text { de conceptualização } \\
\text { imaginação associada com um } \\
\text { campo jurídico particular para o } \\
\text { (proporcionalidade) }\end{array}$ \\
\hline $\begin{array}{l}\text { 7) pluralista } \\
\text { campo global }\end{array}$
\end{tabular}

* Extraído e adaptado de Walker ${ }^{14}$

Além de conflitantes, tais princípios não conseguirão alcançar uma precedência e grande destaque, tal qual a moldura keynesiana-vestfaliana de Estado nacional alcançou nos últimos séculos. Com base em tais considerações, Neil Walker aponta que tais princípios precisam ser discutidos, mas as decisões acerca de qual deles e em que grau serão utilizados para explicar as relações entre as diferentes unidades das ordens mundiais jurídicas e morais, deverão ocorrer, todavia, dentro, precisamente, da mesma moldura geopolítica e cultural das contestadas premissas que queremos resolver. Dito em outras palavras, na medida em que buscamos estabilizar o chão embaixo de nossos pés, no ínterim não podemos ficar em pé sobre nada, a não ser sob o mesmo chão instável ${ }^{15}$. Por enquanto, a única certeza que podemos ter sobre o tema é que a restauração de apenas um princípio dominante de autoridade está descartada.

Portanto, o foco no direito constitucional e em sua soberania será o chão instável para a análise das inter-relações entre os ordenamentos jurídicos internacionais e o interno. Oscar Vieira ${ }^{16}$ considera que os sistemas constitucionais vêm sendo, fortemente, pressionados por diversas demandas impostas por um cenário internacional em rápida configuração, que, ao mesmo tempo em que enfraquece o princípio da soberania vestfaliana (e como reflexo de tais demandas), enseja, no âmbito nacional, o que denominou de realinhamento constitucional.

\footnotetext{
${ }^{14}$ WALKER, Beyond Boundary Disputes and Basic Grids. Op. cit

${ }^{15}$ Sobre o ponto, existem outros problemas: quem deve decidir como iremos especificar a relação global ótima entre unidades que tomam decisões? Existe o problema de capacidade ou de iniciativa: quem está na posição de começar o processo? Quem deve decidir, passado o problema da iniciativa? WALKER, Beyond the grid, op. cit, p. 391-393,

16 VIEIRA, Oscar Vilhena. Realinhamento Constitucional. in SUNDFELD, Carlos Ari; VILHENA VIEIRA, Oscar (coords.) Direito Global. São Paulo: Max Limonad, 1999.
} 
Nesse passo, defende a ideia de que tais demandas acarretam a reformulação, ainda que operando em via dupla, do paradigma constitucionalista clássico. Para o autor, a manutenção dos ideários constitucionais é importante, na medida em que foram eles quem conjugaram segurança ao mundo dos direitos e à democracia, como um mecanismo de auto vinculação, por meio do qual a soberania popular busca se proteger de suas paixões e fraquezas, atribuindo mecanismos de maior rigidez no trato de alterações políticas importantes que devem ser utilizados contra maiorias eventuais, pois se constituem como filtros éticos que nos auxiliam em nosso relacionamento com um mundo em rápida mudança ${ }^{17}$. No entanto, tais premissas precisam ser redimensionadas aos problemas atuais. Sobre o tema, o autor identifica três tendências que acarretariam o realinhamento constitucional de via dupla, quais sejam: 1) o constitucionalismo regional, 2) o cosmopolitismo ético dos direitos humanos e a 3) economia constitucional.

De acordo com o autor, o constitucionalismo regional, tomando como exemplo o modelo desenvolvido pela União Europeia, interpreta o status dos tratados comunitários inserido dentro de um processo de constitucionalização: que seria, ao mesmo tempo, heterodoxo em termos de teoria constitucional, mas constitutivo de uma comunidade jurídica, porquanto transferiria poderes soberanos constitucionais à comunidade europeia, realizando um pacto constituinte continental permitido pelas próprias normas constitucionais dos Estados membros (o aspecto da via dupla) ${ }^{18}$.

Por outro lado, pontua Vieira, o cosmopolitismo ético dos direitos humanos ganhou força após os problemas acarretados pela proteção, isolada, dos Direitos Humanos anteriormente à $2^{2}$ guerra-mundial, o que justificou a necessidade de se fortificar o ideário de direitos compartilhados pelos homens, com base na igualdade e na dignidade humana, impondo, pela via dos sistemas internacionais de proteção dos direitos humanos, prescrições jurídicas para o cumprimento por parte dos estados signatários dos tratados ${ }^{19}$.

Por último, o autor elenca o mais controverso das três demandas, qual seja, a economia constitucional. Oscar Vieira alerta que se trata da maior e mais preocupante fonte de pressão para o realinhamento constitucional, pois o processo de liberalização dos

\footnotetext{
17 VIEIRA, op. Cit., p. 20.

18 Para Amirante, a inclusão de temas, tais como: direito comunitário, direito internacional, relações internacionais, multiplicação de organismos supranacionais, tratados internacionais de direitos humanos, ultrapassa a capacidade analítica dos clássicos cânones metodológicos e hermenêuticos do constitucionalismo continental clássico, atingido doutrina e prática constitucionais. Isto porque, as inúmeras instituições da União Europeia (Parlamento Europeu, Corte de Justiça, Conselho Europeu, Banco Central Europeu etc.) não são facilmente, sem algum desconforto, remissíveis à teoria e prática do constitucionalismo no sentido clássico. Portanto, podemos concluir que as construções teóricas do constitucionalismo clássico no sentido hermenêutico e institucional não são suficientes para explicar as complexidades do direito comunitário. AMIRANTE, Carlo. Uniões supranacionais e reorganização constitucional do Estado. São. Leopoldo: Unisinos, 2003, p. 27-36.

19 Importante ressaltar que, neste ponto, o autor não foi explícito ao indicar qual seria a "outra via" no ponto, limitando-se a indicar a dimensão internacional, deixando inexplorado de que forma os elementos constitucionais poderiam contribuir para o cosmopolitismo ético dos direitos humanos. Não obstante tal ausência, podemos indicar a preocupação dos tribunais internacionais de direitos humanos em construir sua jurisprudência com base nas decisões da jurisdição constitucional dos Estados que compõem o respectivo sistema de proteção. Ou seja, as pautas interpretativas dos Direitos Humanos não surgem do vácuo, mas se desenvolvem a partir dos direitos fundamentais. Sobre o tema, cf. MAGALHÃES, Breno Baía. Pluralismo Constitucional Interamericano: leitura plural da Constituição de 1988 e o diálogo entre o Supremo Tribunal Federal e a Corte Interamericana de Direitos Humanos. 2015. 315 f. Tese (Doutorado em Direito) - Programa de Pós-Graduação em Direito, Universidade Federal do Pará, Belém, 2015.
} 
mercados internacionais contrasta com o constitucionalismo dirigente característico de nossa recente experiência constitucional, porquanto toda a ação interventora estatal é vista como bloqueio para o desenvolvimento das forças do mercado, acarretando na sua ineficiência, em face da competitividade internacional. Como contraponto, o autor afirma que tal pressão deve encontrar limites nas cartas de direitos e em um conjunto de procedimentos para a tomada de decisões democráticas, caso contrário as Constituições perderão sua finalidade, na medida em que as mesmas estabelecem regras de justiça distributiva, que podem interferir nas formas de intervenção estatal. Tais regras devem salvaguardar a reserva de justiça da Constituição ${ }^{20}$.

Nesse sentido, de acordo com os pontos abordados acima, podemos concluir que o Estado deixa de ser o único ator da produção jurídica interna. A Constituição, na posição de estatuto detentor dos critérios formais de produção normativa, é a instituição cujos fundamentos são mais afetados ${ }^{21}$. Por essa razão, o constitucionalismo deve gestar novas formas explicativas de conhecimento e regulação normativa que sejam relevantes para os modernos discursos de interação entre ordenamentos e que sejam imaginativos da complexa política internacional.

Não se trata de defender, no mesmo sentido da crítica desenvolvida por JuliosCampuzano ${ }^{22}$, uma homogeneidade artificial e forçada entre os direitos internacional e o nacional, nem mesmo de suprimir os complexos ordenamentos jurídicos estatais de uma vez por todas, mas sim de pensar em teorias capazes de fornecer elementos para a articulação e interpretação das intricadas interconexões presentes no direito constitucional contemporâneo.

O julgamento do RE 466.343 foi importante para a sensibilização de tal problemática ao constitucionalismo brasileiro. Ressalvando as críticas à hipótese da supralegalidade ${ }^{23}$, a decisão demonstrou que a Constituição e as leis nacionais deverão levar em conta, em suas interpretações ${ }^{24}$ o direito internacional dos direitos humanos, o que demonstra que sustentar

\footnotetext{
${ }^{20}$ VIEIRA, Realinhamento, Op. Cit, p. 28-46. No mesmo sentido de Vieira, Julios-Campuzano defende que não se pode deixar que normas interdependentes das exigências fáticas dos mutantes fluxos normativos transnacionais vulnerem exigências normativas dos valores constitucionais. JULIOS-CAMPUZANO, Alfonso de. Constitucionalismo em tempos de globalização. Porto Alegre: Livraria do Advogado, 2009, p. 65. Além da problemática e controversa pressuposição de que as normas constitucionais representam valores, as posições, no ponto, de Vieira e Julios-Campuzano devem ser contextualizadas com as suas próprias ideias, na medida em que uma defesa irrestrita de supostos valores constitucionais ou de regras mínimas de justiça, podem, exatamente, minar a noção de realinhamento constitucional e de constitucionalismo global, pois as interações entre os ordenamentos seriam, sempre, determinadas pela Constituição e por suas normas. Além de acrescentar pouco à discussão das interconexões entre ordenamentos, a perspectiva apresenta que as referidas interconexões são conduzidas e estão localizadas, exclusivamente, nas Constituições. Talvez uma melhor interpretação esteja na ideia de um Pluralismo Constitucional. Cf. WALKER, Neil. The Idea of Constitutional Pluralism. The Modern Law Review, Vol. 65, no 03, maio, p. 317-359, 2002 e MAGALHÃES, Pluralismo Constitucional, op. cit.

${ }^{21}$ Não apenas por conta do aspecto da produção normativa, mas porque a Constituição encerra, igualmente, normas a respeito do exercício da democracia, dispõe sobre a divisão orgânica e territorial do poder e, principalmente, garante os direitos fundamentais dos cidadãos.

${ }^{22}$ CAMPUZANO, Alfonso de. Constitucionalismo em tempos de globalização. Porto Alegre: Livraria do Advogado, 2009, p. 57.

${ }^{23}$ MAGALHÃES, Breno Baía. O controle difuso de convencionalidade no Brasil: soluções para seu aprimoramento. In: Cássius Guimarães Chai; Elda Coelho de Azevedo Bussinguer; Valena Jacob Chaves. (Org.). Ensaios críticos: do político ao jurídico. Campos dos Goytacazes: Brasil Multicultural, 2016, p. 104-126, p. 116.

${ }^{24}$ Lembremos que a prisão do depositário infiel ainda está positivada na Constituição.
} 
a interpretação das Constituições estaduais em conformidade com o direito internacional é uma ação inevitável ${ }^{25}$.

Portanto, a defesa de uma postura hierarquia acerca da relação entre os ordenamentos jurídicos é de difícil defesa. Tal questão desestimula a visão de perspectiva absoluta de um lado das partes, seja constitucional ou internacional, mas possibilita uma pluralidade de perspectivas (pluralidade de ordens jurídicas), cuja característica principal está na inexistência de uma norma jurídica (que poderia ser coletada em qualquer um dos ordenamentos ${ }^{26}$ ) apta a decidir qual norma deverá prevalecer em casos de eventuais conflitos. Em suma, é problemático sustentar a noção de supremacia entre as ordens jurídicas.

Nesse passo, é importante pontuar que, e tendo em vista o alerta de Walker, as discussões acerca das relações entre as ordens jurídicas não devem partir de um suposto plano de observação privilegiado, capaz de determinar de que forma as interações devem ocorrer. No entanto, seria problemático, igualmente, partir para construções mais amplas acerca de relações internacionais e direito internacional e sua compressão em todos os Estados de forma genérica e descoordenada. Por tais razões, o próximo passo é rediscutir as possíveis formas de interação entre Constituição e Direitos Humanos. Dito em outras palavras, tendo em vista que o chão é movediço, o ponto mais seguro para discutir a perspectiva plural é o constitucional.

\section{PROTEÇÃO MULTINÍVEL dOS DIREITOS hUMANOS: 0 STF E OS TRATAdOS INTERNACIONAIS DE DIREITOS HUMANOS.}

Como ressaltado linhas atrás, os reflexos dos desafios impostos ao constitucionalismo clássico podem ser observados na Constituição de 1988. Sua abertura para questões de Direito Internacional (art. 4ㅇ), o Incidente de Deslocamento de Competência (Art. 109, $\S 5$ ㅇ) e a possibilidade de adesão a Tribunais Internacionais de Direitos Humanos (Art. 7으, do $A D C T),($ Art. $5, \S 4)$, a constitucionalização da submissão à jurisdição do Tribunal Penal Internacional (EC/45) apontam para uma interpretação das normas constitucionais sensível às normas supranacionais. Sem embargo do dito anteriormente, as Reformas Constitucionais ocorridas nos 15 primeiros anos da Constituição acarretaram a abertura do Brasil ao capital estrangeiro e à quebra do monopólio estatal na prestação de serviços públicos, influenciando na alteração do controle dos poderes constitucionais, uma vez que parcela das funções estatais foi terceirizada para agentes privados transnacionais, cabendo ao estado funções fiscalizadoras e mediadoras.

No plano da proteção dos direitos fundamentais, a problemática se agrava, porquanto o Brasil, como parte do Sistema de proteção de Direitos Humanos da OEA, ratifica normas que possuem, em sua essência, conteúdo constitucional. Na medida em que tais normas supranacionais de conteúdo constitucional sobrepõem-se às constitucionais, cuja interpretação se faz por meio da Jurisdição Constitucional brasileira, as interpretações feitas

\footnotetext{
${ }^{25}$ Sobre a necessidade de o STF adotar a ideia de interpretação conforme para dar maior operatividade à tese da supralegalidade, cf. MAUES, Antonio Gomes; MAGALHÃES, Breno Baía. A Recepção dos Tratados de Direitos Humanos pelos Tribunais Nacionais: Sentenças Paradigmáticas de Colômbia, Argentina e Brasil. Direito, Estado e Sociedade, v. 48, p. 76-112, 2016.

${ }^{26}$ No caso do estudo, a Constituição ou um Tratado Internacional de Direitos Humanos.
} 
pela Corte Interamericana de Direitos Humanos e as realizadas pelo STF concernem semelhantes matérias afetas ao constitucionalismo ${ }^{27}$ : o limite da atuação estatal dos Poderes da República por meio de direitos. Ou seja, ambas as cortes atuam, ainda que não estejam institucionalmente vinculadas, em âmbitos de competência coincidentes.

Atuando, portanto, em âmbitos de competências coincidentes, as interpretações que realizam das normas jurídicas de conteúdos substantivos semelhantes, mas de origens diversas, podem conflitar. Do ponto de vista da proteção efetiva dos direitos humanos, é necessário que pensemos em formas para, evitando, sempre, o retorno a considerações de soberania vestefalianas, garantir que os possíveis conflitos na interpretação dos direitos sejam redimensionados, dentro de uma concepção pluralista do marco constitucional brasileiro.

Não desconhecemos que o Brasil deu um importante passo na alteração desta compreensão acerca da soberania vestefaliana no julgamento do Recurso Extraordinário no 466.343/SP, em que foi considerado que a Convenção Americana de Direitos Humanos, vigente em nosso direito interno através do Decreto Presidencial no 678, de 06 de novembro de 1992, possui status de norma supralegal. A maioria do plenário decidiu que, desde a adesão do Brasil, sem qualquer reserva, ao Pacto Internacional dos Direitos Civis e Políticos (art. 11) e à Convenção Americana, não haveria mais base legal para a prisão civil do depositário infiel, pois o caráter especial desses diplomas internacionais sobre direitos humanos lhes reserva lugar específico no ordenamento jurídico, estando abaixo da Constituição, porém acima da legislação interna. Por essa razão, o status normativo supralegal dos tratados de direitos humanos subscritos pelo Brasil torna inaplicável a legislação infraconstitucional com eles conflitantes, seja ela anterior ou posterior ao ato de adesão.

Com efeito, a referida interpretação é mais vantajosa do que a presente no RE $80.004 / \mathrm{SE}$, que adotou a tese de que o conflito entre tratado internacional e lei interna brasileira deveria ser resolvido nos moldes da regra "lei posterior derroga a anterior", porquanto ambas as normas estariam no mesmo nível hierárquico, por conta da introdução do tratado no ordenamento jurídico brasileiro como lei ordinária.

Ainda que a tese da supralegalidade seja amplamente discutível, enquanto interpretação a ser feita dos parágrafos 20 e 30 , do art. 50 da CFRB $/ 88^{28}$, importantes consequências decorrem de tal reconhecimento, partindo de considerações hermenêuticas: qual a melhor forma de equacionar as relações decorrentes do entrelaçamento das diferentes ordens jurídicas concernentes aos direitos humanos?

Se, outrora, o posicionamento jurisprudencial do STF destacava a isolada superioridade hierárquica das normas constitucionais; atualmente, a tese da supralegalidade inseriu novas e importantes variáveis na discussão acerca do papel a ser desempenhado pelas normas internacionais de direitos humanos, conduzindo a uma necessária reinterpretação daquele paradigma ${ }^{29}$.

\footnotetext{
${ }^{27}$ Para uma visão semelhante, mas não idêntica ao defendido aqui, cf. NEVES, Marcelo. Transconstitucionalismo. São Paulo: Martins Fontes, 2009.

28 Para a discussão acerca de tratados sobre direitos humanos e sua caracterização constitucional, cf.. MAGALHÃES, B. B.; SOZINHO, D. T. M. ; CARVALHO, G. B. . Entre a forma e a matéria: a distinção entre tratados internacionais de direitos humanos materialmente e formalmente constitucionais. Revista de Informação Legislativa, v. 201, p. 275-296, 2014.

${ }^{29} \mathrm{O}$ ponto ótimo será a incorporação da interpretação conforme.
} 
O denominado efeito paralisante salientado pelo Min. Gilmar Mendes ${ }^{30}$, ainda que não tenha o condão de reformar ou revogar normas constitucionais, permite a inserção de um padrão normativo intermediário na fiscalização da legislação infraconstitucional. Consequentemente, o STF precisará interpretar o ordenamento nacional, não apenas com base nas normas constitucionais, mas, também, com base nos tratados e com a jurisprudência internacional que versem sobre direitos humanos, porque tais parâmetros interpretativos têm a força de: 1) paralisar a legislação infraconstitucional a eles contrária e 2) estimular a relação da interpretação constitucional com a internacional.

As consequências acima listadas encontram no precedente a via privilegiada para suas concretizações, uma vez que a interpretação judicial dos tratados internacionais desenvolve sua argumentação com base e em torno da noção de precedentes, seja no plano interno ou externo.

Isto pode ser explicado.

Como alertou Böckenförde ${ }^{31}$ as disposições sobre direitos fundamentais são fórmulas que indicam preceitos principiológicos que carecem, em si mesmas, de um sentido interpretativo material único. A miríade de interpretações que podem ser construídas com base em uma mesma disposição textual normativa ${ }^{32}$ não podem ser coletadas (ou mesmo justificadas), simplesmente, em pontos de conexão com a literalidade - ou ainda, no significado meramente semântico da expressão utilizada pela Constituição, mas sim com base em uma teoria relacionada com as compreensões interpretativas acerca do que significam os Direitos Fundamentais no contexto constitucional analisado.

Da mesma forma que os direitos fundamentais, os Direitos Humanos presentes em tratados não podem ter sua interpretação limitada pela semântica de seus dispositivos. Ainda que não necessariamente no viés agora desenvolvido, Piovesan ${ }^{33}$ atesta que as expressões utilizadas pelo constituinte brasileiro no rol dos direitos fundamentais são semelhantes às diversas tratativas internacionais. Caso compreendêssemos a interpretação dos Direitos Humanos com base em uma teoria voluntarista das obrigações no terreno das relações internacionais ${ }^{34}$, a literalidade esvaziaria a função dos tratados.

Ademais, no âmbito interno, a referida abordagem estimularia as cortes a interpretar os tratados com base, tão somente, no texto constitucional ${ }^{35}$, devido à similaridade textual

\footnotetext{
${ }^{30}$ Cf. o RE 466.343, p. 1.160 do acórdão e p. 26 de voto escrito individual do Ministro.

31 BÖCKENFÖRDE, Ernst-Wolfgang. Escritos sobre derechos fundamentales. Tradução de Ignacio Villaverde Menéndez. Baden-Baden: Nomos, 1993

32 Discussões sobre aborto e eutanásia no Brasil, por exemplo, além de guiadas pelos precedentes da ADI 3.510 e da ADPF 54, deverão ser realizadas com base, primordialmente, no seguinte enunciado textual do caput do art. 5 o "inviolabilidade do direito à vida".

33 PIOVESAN, Flávia. Direitos Humanos e o Direito Constitucional Internacional. 2ạ ed. São Paulo: Max Limonad, $1997,115$.

${ }^{34}$ A referida abordagem, que é tradicional no campo do Direito Internacional Público brasileiro, foca sua análise nos estados como os entes que participam das disputas internacionais de acordo com suas vontades e suas relações são regidas por uma frágil forma de regulamentação jurídica amplamente influenciada pelos interesses das partes envolvidas (OONA, Op. Cit., 2002 e PETERS, Anne. There is Nothing More Practical than a Good Theory: An Overview of Contemporary Approaches to International Law. German Yearbook of International Law, Vol. 44, Berlin, 25-37, 2001).

${ }^{35}$ Nesse sentido, cf. antiga jurisprudência do STF acerca da interpretação do revogado art. 594 , do CPP: Esta Corte já firmou o entendimento de que o benefício da apelação em liberdade não se aplica com relação aos recursos extraordinário e especial que não tem efeito suspensivo, o que não é incompatível com a presunção de
} 
entre ambos. Nesse passo, os tratados poderiam ser considerados como uma mera replicação dos textos constitucionais, tornando desnecessária sua citação, pois, no mínimo, suas prescrições normativas estariam absorvidas pelas normas constitucionais (o Brasil é um bom exemplo). Se a função dos tratados se esgotar nas expressões textuais expressas, o prognóstico estará correto. No entanto, tendo em vista a similitude de problemas de moralidade política compartilhados pelos direitos fundamentais e humanos, a interpretação dos tratados é uma prática interpretativa e a semântica auxilia muito pouco na definição do significado de um direito humano ${ }^{36}$. Ou alguém poderia argumentar que foi a semântica dos arts. 04, 05, 07, 08 e 25 da CADH que levou a CtIDH à condenar o Brasil no caso Gomes Lund? Em que justificativa textual perseguições políticas e o dever de o Estado efetivar buscas e reparações eficientes às vítimas de regime de exceção podem ser embasadas? Apenas podemos justificar a interpretação porque uma compreensão sobre o que significa o direito à vida e a função da CADH foram desenvolvidas pela CtIDH por meio de sua fundamentação. Portanto, a citação do texto da CADH desacompanhada da discussão do precedente pouco acrescenta à pratica interpretativa dos direitos humanos/fundamentais ${ }^{37}$.

Além de se tornarem fonte indispensável para a compreensão da Convenção, os precedentes, por essa mesma razão, devem ser observados pelos signatários em casos em que os mesmos não forem parte, uma vez que, em verdade, não é, simplesmente o texto da Convenção que vincula o Estado, mas à sua interpretação. Sendo assim, todas as interpretações realizadas pela CtIDH sobre algum direito humano previsto na convenção devem servir de parâmetro interpretativo ${ }^{38}$.

Ainda que analisando a CEDH, Queralt Jimenez ${ }^{39}$ afirma que o entendimento da interpretação dos direitos convencionais parte e se deduz das sentenças da CtEDH. Pondera que, em virtude de sua importância, deve-se considerar que suas sentenças são importantes o suficiente para ultrapassar o aspecto do caso concreto analisado por repercutirem em assuntos futuros similares, tanto para o Estado em questão, quanto para outros Estados que, eventualmente, se encontrem na mesma situação de violação ${ }^{40}$. Conclui a autora que a CtEDH é a responsável último e subsidiário dos direitos subjetivos e obrigações objetivas reconhecidas pela CEDH e não atua apenas na defesa pontual e concreta. Sua atuação,

\footnotetext{
não-culpabilidade prevista no artigo 5., LVII, da Constituição Federal. - O Plenário do S.T.F. já salientou que a Convenção Americana sobre Direitos Humanos (Pacto de São José da Costa Rica) não assegura, de modo irrestrito, o direito de recorrer em liberdade, ressalvando o disposto na Constituição e nas leis dos Estados-Partes (HC 73151 / RJ , MOREIRA ALVES, DJ 19/04/1996).

${ }^{36}$ LETSAS, George. A Theory of Interpretation of the European Convention on Human Rights. Oxford University Press: Oxford, 2009.

${ }^{37}$ Nesse sentido, de acordo com Queralt Jiménez, afirmar que um juiz nacional utilizou um artigo de um tratado internacional como um argumento independente e forte para resolver determinado assunto, em busca de uma harmonização, não é o mesmo que afirmar que o juiz interno apenas citou a norma como instrumento para reforçar a autoridade de um argumento fundado em um preceito positivado da Constituição interna. No último caso, a citação do tratado seria apenas algo acidental, ao passo que a ausência do argumento não alteraria a substância da manifestação judicial. QUERALT JIMÉNEZ, Argelia, La interpretación de los derechos: del Tribunal de Estrasburgo al Tribunal Constitucional. Centro de Estudios Políticos y Constitucionales: Madrid, 2008.

${ }^{38}$ Trata-se, exatamente, do exercício do controle de convencionalidade exigido pela Corte IDH. Sobre o ponto, cf. Magalhães. O Controle Difuso de convencionalidade, op. Cit.

39 QUERALT JIMÉNEZ, Argelia, La interpretación de los derechos. Ob. cit, p. 64.

40 Tal efeito ocorre nos na Europa, ainda que em graus diversos, como atestaram os estudos compilados em KELLER, Helen; SWEET, Alec Stone (eds.). A Europe of rights: the impact of the ECHR on national legal systems. Oxford: Oxford University Press, 2008.
} 
portanto, é mas mais ampla na garantia dos padrões europeus comuns que garantem a efetividade do sistema, além de estimular uma função protetiva preventiva da CEDH.

Nesse passo, o constitucionalismo brasileiro não deve ater-se, somente, aos casos em que o Brasil for parte ou que tenha sido condenado, mas garantir o diálogo em todos os casos em que questões de sensíveis de moralidade política estiverem envolvidas na interpretação dos direitos dos cidadãos, seja no nível interno ou externo.

\section{DIÁLOGO ENTRE PRECEDENTES COMO POSSÍVEL FORMA DE ARTICULAÇÃO}

Com base no descrito na seção anterior, inúmeras propostas teóricas intencionaram inserir no ideal do constitucionalismo brasileiro (tradicionalmente relacionado às experiências dos estados nacionais) a problemática internacional dos direitos humanos como matéria inerente ao papel da Constituição e, obviamente, da jurisdição constitucional, para, consequentemente, prescrever as formas de inter-relações entre as ordens jurídicas.

Inspirado na classificação de Marcelo $\mathrm{Neves}^{41}$, podemos elencar três modelos de propostas teóricas sobre o problema acima descrito: a) o modelo da resistência, que atribui caráter primordial à Constituição e secundário ao Direito internacional, situando o último em níveis hierárquicos inferiores à primeira; b) o modelo da convergência, defendendo a uniformização dos parâmetros interpretativos internacionais e constitucionais, porque ambos estariam dispostos horizontalmente, ou seja, ambos possuiriam a mesma hierarquia ${ }^{42}$ e b) modelos da articulação: que, ao invés de discutir problemas relacionados à hierarquia das ordens jurídicas, ou a necessidade de uma uniformização interpretativa, preconizam o diálogo e as decisões baseadas em uma racionalidade deliberativa e não adversarial, no intuito de resolver os problemas comuns desta parte do constitucionalismo, qual seja, a defesa dos Direitos Humanos ${ }^{43}$.

A metáfora do diálogo sustentada pelo modelo da articulação é atrativa, do ponto de vista normativo, para a compreensão sobre a relação da interpretação judicial dos direitos humanos (realizada pelos tribunais supranacionais e cortes constitucionais ou supremas). Ora, uma vez que os referidos tribunais estão engajados na interpretação de um mesmo conjunto de normas jurídicas; enfrentando problemas semelhantes do ponto de vista constitucional (limitação do poder e proteção de direitos) e utilizando a mesma linguagem (jurídica), de maneira metafórica, ambas as cortes estão engajadas em um diálogo, ou seja, nenhuma delas pode arrogar para si o papel de detentora de autoridade última e final sobre a intepretação de determinado conjunto normativo.

Claro, ainda que metafórico, o diálogo entre as cortes exige, pelo menos, dois pressupostos importantes: 1) inexistência de subordinações hierárquicas - queremos diálogo, não a imposição vertical de interpretações e 2) troca mútua de experiências: um simples monólogo, beirando à deferência, não se presta ao ideário dialógico do aprendizado

\footnotetext{
${ }^{41}$ NEVES, Transconstitucionalismo, op. Cit.

${ }^{42}$ Como exemplos, podemos citar Piovesan, Direitos Humanos, op. Cit,.

43 NEVES, Transconstitucionalismo, op. Cit e SILVA, Virgílio Afonso da. Integração e diálogo constitucional na América do Sul. BOGDANDY, Armin von; PIOVESAN, Flávia; ANTONIAZZI, Mariela Morales (orgs.) Direitos humanos, democracia e integração jurídica na América do Sul. Rio de Janeiro: Lumen Juris, 2010, p. 515-530
} 
recíproco. De pronto podemos observar que as exigências prescritivas do diálogo entre as cortes devem conciliar-se com a reinterpretação do constitucionalismo.

Como apontado mais acima, o Estado deixa de ser o palco exclusivo das relações de limites ao poder estatal. Não apenas no sentido de que o mesmo transporta parcela de poder para entidades supranacionais, mas também no sentido de que tal transporte encerra a importante ideia de que problemas constitucionais podem transbordar das fronteiras territoriais dos Estados.

Nesse passo, a interpretação da Constituição não pode ficar limitada a compreensões paroquias, na medida em que a preocupação dos sistemas regionais de proteção não é substituir a interpretação das supremas cortes e dos tribunais constitucionais, mas complementar a proteção dos Direitos Humanos, daí a importância da construção de uma harmônica proteção multinível. Portanto, se a noção de complementariedade é ínsita aos sistemas regionais de proteção dos direitos humanos, não podemos falar de uma primazia do direito internacional, nem de uma subordinação do direito constitucional ou vice-versa.

Ademais, retomando a questão da difusão do poder estatal dentro de um contexto pós-soberania vestefaliana, a erosão dos modelos de totalidade estatal e isolamento dos assuntos constitucionais a um espaço territorial delimitado possibilitou o surgimento de um sistema internacional em que a pluralidade de centros de poder tomasse o lugar antes ocupado, solitariamente, pelo estado nacional ${ }^{44}$. Seja do ponto de vista regional ou global, os ordenamentos jurídicos constitucionais perderam a primazia da regulamentação de suas competências clássicas, quais sejam: o monopólio da produção de normas jurídicas e a capacidade de solucionar, sem interferências externas, assuntos relacionados a Direitos Humanos. Por tais razões, justifica-se analisar como o constitucionalismo brasileiro pode responder ao quadro descrito.

A CADH, por exemplo, alçada ao status supralegal, foi lembrada pelo STF em um pequeno número de casos, embora considerados emblemáticos para o constitucionalismo brasileiro, como, por exemplo: 1) no caso da decisão acerca da não recepção da Lei de Imprensa pela CF/88 (ADPF $130^{45}$ ); 2) na declaração de inconstitucionalidade de DL que previa a diplomação superior como requisito para exercício da profissão de jornalista, no RE $511.961 / \mathrm{SP}^{46}$; 3) no julgado em que permitiu a extraditando o direito à assistência consular (EXT $\left.1.126^{47}\right)$; 4) nas hipóteses de manutenção de decreto presidencial que estabelecia ampla área de terras indígenas demarcadas, na Pet. $3.388 / \mathrm{RR}^{48}$; 5) ainda que para se afastar da

\footnotetext{
${ }^{44}$ Cf., nesse sentido, Slaughter, Sovereignty and Power in a Networked World Order, ob. Cit, p. 286-287.

45 ADPF 130, DJe 06/11/2009, Rel. Ayres Britto. A CADH foi citada pelo Ministro Menezes Direito para pontuar que a convenção previa a proteção, além do direito à liberdade de expressão, de direitos acerca do patrimônio moral do indivíduo (art. 19), que implicavam na possibilidade de alguma forma de intervenção legislativa no tema. O Ministro Celso de Mello citou a CADH para lembrar que a liberdade de expressão não franqueia qualquer manifestação, como o ódio racial (art. 13) e citou a OC 07/86, da CtIDH, para sustentar que o direito à liberdade expressão inclui o direito de todos a obter a informação certa e precisa.

${ }^{46}$ RE 511.961/SP, DJe 13/11/2009, Rel. Gilmar Mendes. O relator citou extenso trecho da OC 05/85, da CtIDH, que defendia a impossibilidade de diploma para jornalistas, com base na liberdade de expressão.

${ }^{47}$ Ext 1.126 (Alemanha), DJe 11/12/2009, Rel. Joaquim Barbosa. A OC 16/99, da CtIDH, foi citada pelo Ministro Celso de Mello para garantir assistência consular ao extraditando, assim como, ainda com base na opinião consultiva, de outras garantias oriundas do devido processo legal desenvolvidas pela CtIDH.

48 Pet. 3.388/RR, DJe 01/07/2010, Rel. Ayres Britto. O caso Awas Tingni v. Nicaragua (2001) foi citado pelo Ministro Menezes Direito para alertar, negativamente, que os direitos indígenas de propriedade eram considerados como importantes para a comunidade internacional. O Ministro Marco Aurélio, ao criticar a ideia
} 
interpretação atribuída à CADH pela CtIDH na ADPF 153 que decidiu pela constitucionalidade da Lei de Anistia brasileira ${ }^{49}$; 6) na decisão conjunta das ADPF 132 e ADI 4277, em que se discutia possibilidade de extensão às uniões homoafetivas a mesma proteção outorgada à família ${ }^{50}$; 7) no julgamento da AP 470 , quando se discutia a possibilidade de julgamento dos réus atraídos pela conexão à julgamento em última instância pelo $\mathrm{STF}^{51} \mathrm{e}$, posteriormente, como norma capaz de justificar a aplicação e o julgamento dos embargos infringentes previsto no Regimento Interno do STF ${ }^{52}$ e 8) na decisão acerca da inconstitucionalidade da utilização de inquéritos e ações penais em curso como antecedentes para fins de majoração da pena acima do mínimo legal no RE 591.054/SC ${ }^{53}$.

Independentemente do impacto de tais citações nos casos constitucionais apresentados, após a decisão da supralegalidade, os ministros do STF passaram a utilizar a CADH e a jurisprudência da CtIDH, ainda que não na frequência desejada, sugerindo formas de interação com o direito internacional que se distanciam de perspectivas, meramente, hierárquicas, na medida em que a CADH passa a ser encarada como fator a ser levado em consideração na interpretação constitucional.

\section{CONSIDERAÇÕES FINAIS}

A complexidade das relações entre declarações de Direitos Humanos sobrepostas, geralmente de conteúdos diversos, que concorrem em um mesmo espaço geográfico tem gerado inúmeras inquietações quanto às soluções teóricas constitucionais desenvolvidas para solucionar possíveis conflitos entre Direitos Humanos.

do relator de que o modelo de demarcação contínua de terras indígenas seria constitucionalmente exigido, alertou que o Brasil poderia ser responsabilizado internacionalmente por violação do art. 21, da CADH (direito de propriedade) titularizado pelos fazendeiros.

${ }^{49}$ ADPF 153, DJe 06/08/2010, Rel. Eros Grau. O relator afastou os precedentes da CtIDH denominados pelo próprio de fantasmas, com base na data anterior à ação da aceitação da jurisdição contenciosa da CtIDH. O Ministro Celso de Mello citou os casos Barrios Altos v Peru (2001), Loayza Tamayo v. Peru (1997) e Almonacid Arellano v Chile (2006) para afastar sua aplicabilidade ao caso, argumentando que nos casos julgados pela CtIDH as leis eram de autoanistia, portanto, diversas da lei brasileira, fruto de acordo político. O Ministro Lewandowski, divergindo do relator, citou os casos Baldeón-García v. Peru (2006), Massacre de Pueblo Bello v. Colômbia (2006) e Masacre de Mapiripán v. Colômbia (2005) para justificar o dever do Estado brasileiro de investigar e punir os delitos que implicaram em violações graves de Direitos Humanos.

${ }^{50}$ ADPF 132 e ADI 4277, DJe 14/10/11, Rel. Ayres Britto. A CADH foi citada pelo Ministro Luiz Fux para afirmar que o preceito da igualdade previsto na Constituição era uma explicitação proveniente de tratados internacionais, a fim de demonstrar que os casais homossexuais deveriam possuir tratamento semelhante ao casal heterossexual e o Ministro Marco Aurélio, no desenvolvimento da ideia de que caberia a cada indivíduo formular as escolhas de vida que levarão para o desenvolvimento da personalidade, remeteu ao conceito desenvolvida pela CtIDH de "projeto de vida" e citou os casos Loayza Tamayo v. Peru (1997); Cantoral Benavides v. Peru (2001) e Gutiérrez Soler v. Colômbia (2005).

${ }^{51}$ QO de na AP 470, DJ 22/04/2013, Rel. Joaquim Barbosa.

52 260 AgR na AP 470, DJ 17/02/2014, Rel. Roberto Barroso. Na ocasião, foram citados os casos Barreto Leiva v. Venezela (2009) pelos Ministros Luiz Fux (ainda que para afastar sua aplicabilidade ao caso), Lewandowski (indiretamente) e Celso Mello e Mohamed v. Argentina (2012), citado pelo Ministro Teori Zavascki.

${ }^{53}$ Relator Marco Aurélio, Tribunal Pleno, DJe 26/02/2015. O ministro Marco Aurélio citou os casos Cantoral Benavides (2000), Ricardo Canese (2004), Tibi (2004) Cabrera García e Montiel Flores (2010) para reforçar a incidência da presunção de inocência até o trânsito em julgado da sentença condenatória. 
O ordenamento jurídico brasileiro estrutura uma proteção multinível de direitos humanos, que engloba a declaração de direitos prevista no ordenamento constitucional e os tratados internacionais sobre direitos humanos em nível global e regional. O conteúdo dos direitos humanos desenvolvido pelos diferentes níveis de proteção converge em poucas ocasiões, exigindo dos órgãos nacionais, especialmente, do Poder Judiciário, que desenvolva formas de lidar com as interpretações divergentes dos outros níveis.

De acordo com os pontos assentados em parágrafos anteriores, modelos baseados em proposições de resistência e de convergência podem acarretar problemas constitucionais importantes. Por um lado, um posicionamento de resistência, do ponto de vista da interpretação do constitucionalismo brasileiro, enfraquece a proteção dos Direitos Humanos pelas seguintes razões: 1) o descumprimento de compromissos internacionais pode acarretar a responsabilização do Estado, que, atualmente, intencionou reforçar a fiscalização do cumprimento das tratativas internacionais com a criação do IDC (art. 109, § 5ㅇ); 2) a manutenção de uma interpretação da soberania estatal de acordo com paradigmas vestefalianos parece desconsiderar a interpretação das normas constitucionais que estabelecem a prevalência dos direitos Humanos (art. 4으, II, da CF/88) e da participação do Estado em Tribunais internacionais de Direitos Humanos (Art. 7으, do ADCT), bem como as inevitáveis consequências da globalização incorporadas nas reformas constitucionais e 3) a recusa à incorporação de normativas transnacionais diminui o padrão de proteção que pode ser conferido aos Direitos Fundamentais.

De outro lado, diametralmente oposto, um modelo de completa verticalização e convergência apresenta os seguintes problemas: 1) ainda que o paradigma da soberania inconteste do estado nacional esteja sob questionamento, a primazia do Direito Internacional apenas substitui a noção de soberania estatal por outra, transferindo consigo todos as críticas feitas àquela; 2) a regra da subsidiariedade, inerente aos sistemas de proteção internacional de direitos humanos ${ }^{54}$, não se fundamenta em uma premissa de substituição, mas de complementariedade ${ }^{55}$ e 3) a possibilidade de ocorrerem violações com a diminuição dos padrões de proteção dos Direitos Fundamentais, quando a Constituição oferecer padrões maiores e particulares às especificidades da comunidade política.

Deste modo, um modelo voltado para a articulação da intepretação de problemas constitucionais (proteção de direitos) parece ser o que melhor justifica a atuação conjunta de Cortes em âmbitos domésticos e internacionais. Todavia, tal qual os modelos anteriores, existem algumas questões que precisam ser postas em consideração acerca do referido modelo, ponto que precisará de aprofundamento em outra oportunidade.

\section{REFERÊNCIAS}

AMIRANTE, Carlo. Uniões supranacionais e reorganização constitucional do Estado. São. Leopoldo: Unisinos, 2003.

BÖCKENFÖRDE, Ernst-Wolfgang. Escritos sobre derechos fundamentales. Tradução de Ignacio Villaverde Menéndez. Baden-Baden: Nomos, 1993.

\footnotetext{
${ }^{54}$ Arts. 48 a 50, da CADH.

${ }^{55}$ Art. 29, b, da CADH.
} 
BOGDANDY, Armin Von. Pluralism, Direct Effect, and the Ultimate Say. International Journal of Constitutional Law, Vol. 6, n. 3 \& 4, 2008, 397-413, p. 399-400.

DIMOULIS, Dimitri; MARTINS, Leonardo. Teoria Geral dos Direitos Fundamentais. 2a tiragem. São Paulo: Revista dos Tribunais, 2008.

FARIA, José Eduardo. O Direito na economia globalizada. São Paulo: Malheiros Editores, 1999.

GRIFFITHS, John. What is Legal Pluralism? Journal of Legal Pluralism, $n=24,1986$, p. 1-55.

HATHAWAY, Oona. Do Human Rights Treaties Make a Difference? The Yale Law Journal, Vol. 111, p.1935-2041, 2002.

JULIOS-CAMPUZANO, Alfonso de. Constitucionalismo em tempos de globalização. Porto Alegre: Livraria do Advogado, 2009.

KELLER, Helen; SWEET, Alec Stone (eds.). A Europe of rights: the impact of the ECHR on national legal systems. Oxford: Oxford University Press, 2008.

LETSAS, George. A Theory of Interpretation of the European Convention on Human Rights. Oxford University Press: Oxford, 2009.

MAGALHÃES, Breno Baía. O controle difuso de convencionalidade no Brasil: soluções para seu aprimoramento. In: Cássius Guimarães Chai; Elda Coelho de Azevedo Bussinguer; Valena Jacob Chaves. (Org.). Ensaios críticos: do político ao jurídico. Campos dos Goytacazes: Brasil Multicultural, 2016, p. 104-126.

. O sincretismo teórico na apropriação das teorias monista e dualista e sua questionável utilidade como critério para a classificação do modelo brasileiro de incorporação de normas internacionais. Revista de Direito Internacional, v. 12, no 02, p. 7796, 2015.

. Pluralismo Constitucional Interamericano: leitura plural da Constituição de 1988 e o diálogo entre o Supremo Tribunal Federal e a Corte Interamericana de Direitos Humanos. 2015. 315 f. Tese (Doutorado em Direito) - Programa de Pós-Graduação em Direito, Universidade Federal do Pará, Belém, 2015.

MAGALHÃES, Breno Baía ; SOZINHO, D. T. M. ; CARVALHO, G. B. . Entre a forma e a matéria: a distinção entre tratados internacionais de direitos humanos materialmente e formalmente constitucionais. Revista de Informação Legislativa, v. 201, p. 275-296, 2014.

MAUES, Antonio Gomes; MAGALHÃES, Breno Baía. A Recepção dos Tratados de Direitos Humanos pelos Tribunais Nacionais: Sentenças Paradigmáticas de Colômbia, Argentina e Brasil. Direito, Estado e Sociedade, v. 48, p. 76-112, 2016.

NEVES, Marcelo. Transconstitucionalismo. São Paulo: Martins Fontes, 2009.

PETERS, Anne. There is Nothing More Practical than a Good Theory: An Overview of Contemporary Approaches to International Law. German Yearbook of International Law, Vol. 44, Berlin, 25-37, 2001.

PIOVESAN, Flávia. Direitos Humanos e o Direito Constitucional Internacional. 2a ed. São Paulo: Max Limonad, 1997.

QUERALT JIMÉNEZ, Argelia, La interpretación del los derechos: del Tribunal de Estrasburgo al Tribunal Constitucional. Centro de Estudios Políticos y Constitucionales: Madrid, 2008. 
SILVA, Virgílio Afonso da. Integração e diálogo constitucional na América do Sul. BOGDANDY, Armin von; PIOVESAN, Flávia; ANTONIAZZI, Mariela Morales (orgs.) Direitos humanos, democracia e integração jurídica na América do Sul. Rio de Janeiro: Lumen Juris, 2010, p. 515-530.

SLAUGHTER, Anne-Marie. Sovereignty and Power in a Networked World Order. Stanford Journal of International Law, n. 40, 2004, p.283-327.

TEIXEIRA, Anderson Vinchinkeski. Teoria Pluriversalista do Direito Internacional. São Paulo: WMF Martins Fontes, 2011.

VIEIRA, Oscar Vilhena. Realinhamento Constitucional. In: SUNDFELD, Carlos Ari; VILHENA VIEIRA, Oscar (coords.) Direito Global. São Paulo: Max Limonad, 1999.

WALKER, Neil. The Idea of Constitutional Pluralism. The Modern Law Review, Vol. 65, no 03, maio, p. 317-359, 2002

WALKER, Neil. Beyond Boundary Disputes and Basic Grids: Mapping the Global Disorder of Normative Orders, Vol. 6, no 3 e 4, International Journal of Constitution Law, 373-396, 2008. 